\title{
EFFECT OF ANTIMONY ON GRAPHITE GROWTH IN DUCTILE IRON
}

\author{
Lutz Dekker \\ Stahlwerk Bous GmbH, Saarstraße, 66359 Bous, Germany \\ Babette Tonn $(1)$ \\ Institute of Metallurgy, Clausthal University of Technology, Robert-Koch-Str. 42, 38678 Clausthal-Zellerfeld, Germany \\ Gerhard Lilienkamp \\ Institute of Energy Research and Physical Technologies, Clausthal University of Technology, Leibnizstraße 4, 38678 \\ Clausthal-Zellerfeld, Germany
}

Copyright (C) 2020 The Author(s)

https://doi.org/10.1007/s40962-020-00434-1

\begin{abstract}
Antimony is used in ductile cast iron melts to avoid graphite degenerations like exploded graphite and chunky graphite. However, the effect of $\mathrm{Sb}$ in the melt on the crystallization of ductile cast iron is still unknown, therefore the aim of our investigations. The current study presents thermodynamic calculations showing that at the beginning of the eutectic solidification, $\mathrm{Mg}_{3} \mathrm{Sb}_{2}$ is formed. Furthermore, the amount of Sb increases in the austenite and decreases in the remaining melt during solidification. An experiment was conducted, in which a higher amount of $\mathrm{Sb}$ than usual was added to a ductile iron melt. In the microstructure of the Sb-containing sample, a higher gra-

electron microscopy with energy-dispersive X-ray spectroscopy, it could be shown that Sb-containing phases have been formed, which are located in the pearlitic matrix and also in graphite spheroids. As a result of spectroscopic investigations, it can be assumed that Sb-containing phases act as nucleant for graphite nucleation. Further investigations by Auger electron spectroscopy showed that a thin layer of $\mathrm{Sb}$ at the interface between graphite and matrix has been formed. It seems that this layer constricts the diffusion of carbon to the spheroidal graphite and acts as a surfactant favoring a layer-by-layer growth of the graphite spheroids.
\end{abstract} phite precipitate count was measured than in the reference sample without $S b$. The graphite spheroids of the Sb-containing sample show an almost perfect roundness and a very smooth surface. However, lamellar outgrowths from the graphite spheroids were also observed. Using scanning
Keywords: ductile cast iron, antimony, graphite nucleation, graphite growth, auger electron spectroscopy

\section{Introduction}

During solidification of mostly thick-walled ductile iron castings, the graphite has a tendency to degenerate during eutectic growth, which results in exploded or even chunky graphite. Possible reasons are long solidification times, high amounts of $\mathrm{Si}$ and the presence of $\mathrm{Ce}$ in the melt. ${ }^{1}$

This paper is an invited submission to IJMC selected from presentations at the 2nd Carl Loper 2019 Cast Iron Symposium held September 30 to October 1, 2019, in Bilbao, Spain.
According to References 2-4, small amounts of $\mathrm{Pb}, \mathrm{Bi}$ or $\mathrm{Sb}$ in a defined stoichiometric ratio with $\mathrm{Ce}$ can neutralize the detrimental effects of $\mathrm{Ce}$ on graphite growth by forming intermetallic phases in the melt. That is why mainly in large ductile iron castings very small amounts of $\mathrm{Sb}$ between 20 and $40 \mathrm{ppm}$ are added to the cast iron melt to avoid the formation of chunky graphite. Even in ductile cast irons without any $\mathrm{Ce}$ in the melt, the addition of $\mathrm{Sb}$ to the melt is a proven instrument to suppress these undesirable graphite morphologies. 
Kovac $^{5}$ and Liu et al. ${ }^{6}$ detected $\mathrm{Sb}$ at the interface between graphite spheroids and matrix. Kovac assumed that $\mathrm{Sb}$ is blocking the transfer of $\mathrm{C}$ from the melt or from austenite to the spheroids. Liu et al. proposed that $\mathrm{Sb}$ acts as a scavenger for the harmful effects of oxygen at the interface between graphite spheroids and the melt.

However, there is no detailed knowledge about the effect of $\mathrm{Sb}$ on the graphite growth during the solidification of ductile iron melts. The present study was initiated to allow further insights into the mechanism of $\mathrm{Sb}$ on the crystallization of ductile iron melts.

\section{Thermodynamic Calculations}

Thermodynamic calculations using the THERMOCALC database SSOL4 were performed to simulate the phase formation as well as the distribution of $\mathrm{Sb}$ in the melt and in the austenite during the solidification of ductile iron. Here, a local thermodynamic equilibrium is assumed at the interface between solid and liquid. Assuming full miscibility in liquid phase and complete suppression of diffusion in solid phase, the Scheil-Gulliver model was used. For the thermodynamic calculations, the elements $\mathrm{Fe}, \mathrm{C}, \mathrm{Si}, \mathrm{Mn}$, $\mathrm{Mg}$ and $\mathrm{Sb}$ were considered. The element contents were taken from the experiment of the Sb-containing melt and are given in Table 2. Figure 1 shows the calculated formation of solid phases during solidification.

The solidification starts with the formation of primary austenite at a temperature of $1173{ }^{\circ} \mathrm{C}$ followed by the eutectic solidification beginning at $1167^{\circ} \mathrm{C}$. Almost simultaneously with the eutectic growth, the formation of $\mathrm{Mg}_{3} \mathrm{Sb}_{2}$ starts at $1166^{\circ} \mathrm{C}$. No more $\mathrm{Mg}_{3} \mathrm{Sb}_{2}$ phase will be formed from about $1150{ }^{\circ} \mathrm{C}$ until the end of solidification due to a strongly decreasing $\mathrm{Mg}$ content in the liquid, shown in Figure 2.

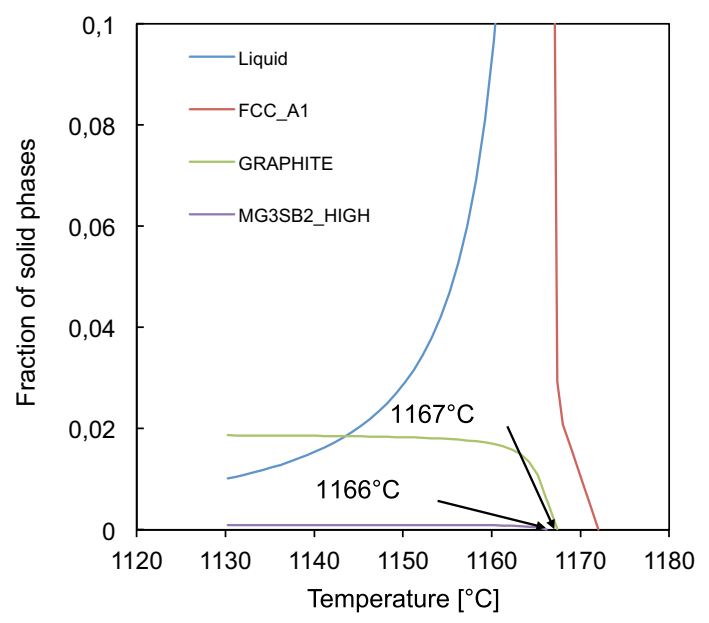

Figure 1. Calculated phase formation during solidification of ductile cast iron.

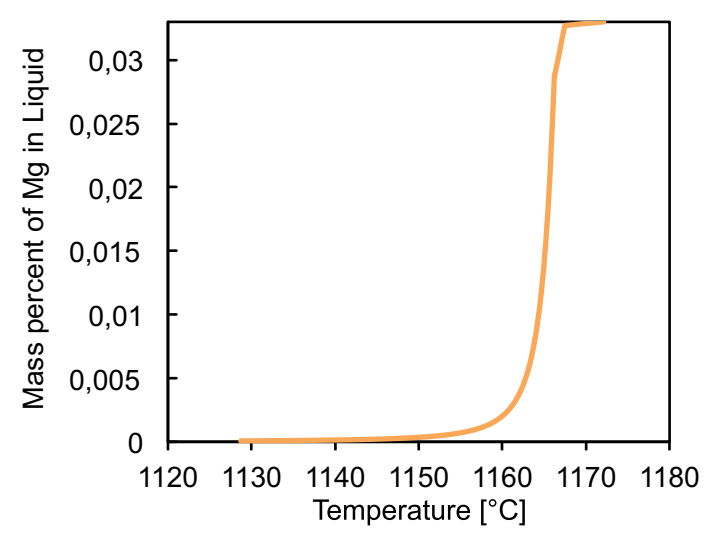

Figure 2. Calculated amount of $\mathrm{Mg}$ in the melt during solidification of ductile iron.

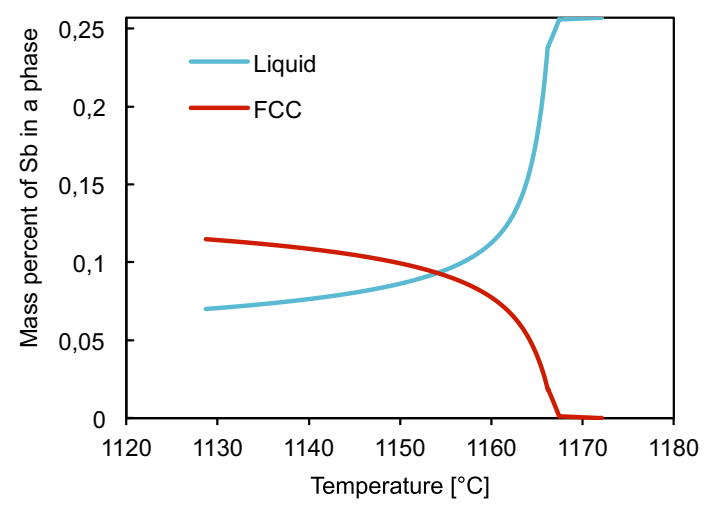

Figure 3. Calculated amount of $\mathrm{Sb}$ in the melt and in austenite during solidification of ductile iron.

Figure 3 shows the calculated development of the amounts of antimony in austenite and in the remaining liquid during solidification. From the results, it can be assumed that $\mathrm{Sb}$ is also solute in austenite.

\section{Experimental}

For the investigation of the effect of $\mathrm{Sb}$ on the graphite morphology, a furan resin-based sand mold with two rectangular-shaped cavities of $60 \times 60 \times 25 \mathrm{~mm}$ size was prepared. For addition of $\mathrm{Sb}$ to the ductile cast iron melt, an in-mold addition process was applied, which means that into one of the cavities $1.9 \mathrm{~g}$ technically pure, fine-grained $\mathrm{Sb}$ was placed. Such a high content of $\mathrm{Sb}$ was chosen in order to increase the probability of detecting it in the microstructure of ductile cast iron.

Furthermore, a ductile cast iron melt was prepared. The base melt, consisting of pig iron, ductile iron returns and steel scrap, was melted in a medium frequency induction furnace with a melt capacity of $35 \mathrm{~kg}$. FeSi75 and graphite were added to reach the target chemical composition. The melt was treated at $1505{ }^{\circ} \mathrm{C}$ with a $\mathrm{Mg}$-containing master alloy. The composition of the master alloy was determined 
Table 1. Chemical Composition (wt\%) of the Mg-Containing Master Alloy

\begin{tabular}{lllll}
\hline $\mathrm{Si}$ & $\mathrm{Mg}$ & $\mathrm{Ca}$ & $\mathrm{Al}$ & $\mathrm{Fe}$ \\
\hline 46.32 & 5.90 & 1.63 & 0.41 & Rest \\
\hline
\end{tabular}

by inductively coupled plasma optical emission spectrometry and is given in Table 1 .

An additional inoculation was not performed. The melt was cast at $1370{ }^{\circ} \mathrm{C}$ into the mold and cooled down to room temperature. The chemical composition of the ductile cast iron was determined by inductively coupled plasma optical emission spectrometry, respectively, by carrier gas hot extraction for determining the contents of carbon and sulfur.

In Table 2, the chemical compositions of the reference specimen and the $\mathrm{Sb}$-containing specimen are given.

Samples of $10 \times 10 \times 6 \mathrm{~mm}$ were taken out of the geometrical center of the cast cuboids and grinded and polished. A deep-etching process using $3 \% \quad \mathrm{HNO}_{3}$ was performed to visualize the surface of graphite nodules. For microstructure investigations, light microscopy and scanning electron microscopy were used. Besides EDX, Auger electron spectroscopy (AES) has been applied to localize the added $\mathrm{Sb}$ in the specimens. The Auger system consists of a scanning electron microscope modified for ultrahigh vacuum and a hemispherical electron energy analyzer (Omicron $\mathrm{GmbH})$. The advantage of AES is the high spatial resolution that is of the order of the electron beam diameter in lateral direction (here a few nanometer) and 1-4 $\mathrm{nm}$ perpendicular to the surface. The depth resolution is determined by the inelastic mean free path of the Auger electrons which is of the order of $0.5 \mathrm{~nm}$ for electrons in the energy range of 50-200 eV and continuously rising up to about $4 \mathrm{~nm}$ for electrons from 200 to $2000 \mathrm{eV}$. Because of such a small probed volume, it is possible to detect fractions of a monolayer of an element at surfaces or interfaces. A quantitative analysis can be performed by employing the concept of sensitivity factors. ${ }^{7}$

Table 2. Chemical Compositions (wt\%) of Cast Iron Specimens

\begin{tabular}{cllllllll}
\hline Melt & $\mathrm{CE}$ & $\mathrm{C}$ & $\mathrm{Si}$ & $\mathrm{Mn}$ & $\mathrm{S}$ & $\mathrm{Mg}$ & $\mathrm{Sb}$ & $\mathrm{Fe}$ \\
\hline $\begin{array}{r}\text { SG- } \\
\text { R }\end{array}$ & 4.14 & 3.38 & 3.01 & 0.11 & 0.018 & 0.033 & 0.001 & Rest \\
$\begin{array}{r}\text { SG- } \\
\text { Sb }\end{array}$ & 4.14 & 3.38 & 3.01 & 0.11 & 0.018 & 0.033 & 0.257 & Rest \\
\hline
\end{tabular}

$\mathrm{CE}=$ Carbon Equivalent $=\mathrm{wt} \% \mathrm{C}+0.25 \mathrm{wt} \% \mathrm{Si}-0.027 \mathrm{wt} \%$

$\mathrm{Mn}+0.4 \mathrm{wt} \% \mathrm{~S}$

\section{Results}

In Figure 4, the graphite morphologies in the geometric centers of both non-etched specimens are shown. In the microstructure of the specimen SG-R in Figure 4a first indications of exploded graphite can be observed. The graphite nodule count amounts to $156 \mathrm{~mm}^{-2}$. The microstructure in Figure $4 \mathrm{~b}$ shows, besides almost perfectly formed graphite spheroids, lamellar outgrowths from the graphite spheroids as well as intergranular flake graphite. This is a typical form of graphite degeneration caused by $\mathrm{Sb}^{4}{ }^{4}$ In the Sb-containing specimen SG-Sb, the graphite nodule count is $197 \mathrm{~mm}^{-2}$.

Figure 5 shows a graphite spheroid embedded in a fully ferritic matrix from the deep etched specimen SG-R. The surface can be described as a coarse and partially rugged structure.

In Figure 6, a graphite spheroid of the deep etched specimen SG-Sb is presented, which is embedded in the lamellar structure of pearlite. The pearlitic structure is caused by the high amount of $\mathrm{Sb}$ in ductile cast iron.

The graphite spheroid in the Sb-containing specimen is characterized by a high roundness and very smooth surface. However, lamellar graphite outgrowing from spheroids can occasionally be observed, shown in Figure 7.

Looking at the locations of $\mathrm{Sb}$ in the microstructure of the specimen SG-Sb, scanning electron microscopy combined with EDX and AES was used, respectively. In the microstructure of the deep etched specimen SG-Sb, small phases, characterized by bright dots, are finely distributed in the pearlitic matrix, Figure 8a. At a higher magnification in Figure 8b, different phases can be seen in the matrix. A semiquantitative EDX analysis was used for determining the compositions of the phases, listed in Table 3. The Sbcontaining phases are located inside the matrix as well as at grain boundaries. Regarding the thermodynamic calculations, these might be $\mathrm{Mg}_{3} \mathrm{Sb}_{2}$ phases, which have been formed during solidification. The bigger angular phases in Figure $8 \mathrm{~b}$ do not contain $\mathrm{Sb}$ and might be $\mathrm{Fe}_{3} \mathrm{P}$ and $\mathrm{TiC}$ or $\mathrm{NbC}$ mixed phases, respectively.

In Figure 9, a SEM-EDX mapping shows $\mathrm{Mg}, \mathrm{S}$ and $\mathrm{Sb}$ in the center of a graphite spheroid. This indicates that beside the usual found substrates based on $\mathrm{Mg}, \mathrm{S}, \mathrm{Al}$ or $\mathrm{Si}$ also MgSbS-containing particles might have acted as substrates for the graphite nucleation.

We also investigated graphite spheroids' substrates by AES. Unfortunately, substrates inside the graphite spheres are not accessible by AES because of the small escape depth of Auger electrons. Thus, we examined substrates in polished specimens, where some nucleants are excavated. Figure 10a shows an example of such a substrate 


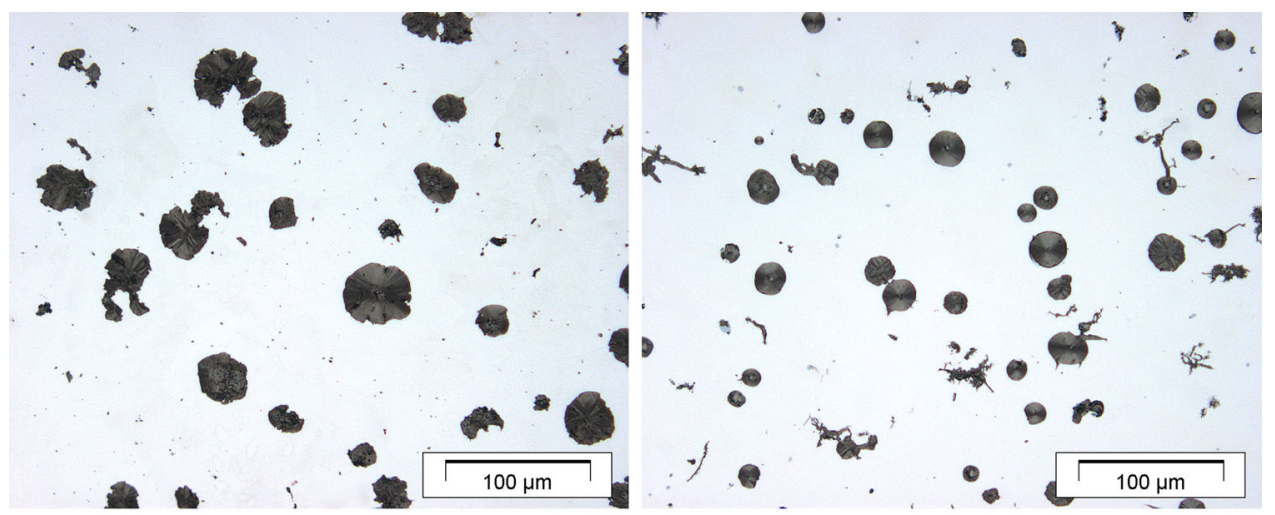

(a)

(b)

Figure 4. Microstructure of specimens without Sb (a) and with 0.26 wt\% Sb (b) in polished and unetched condition.

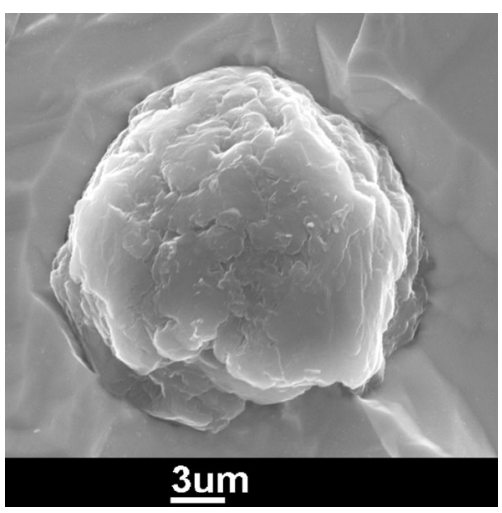

Figure 5. SEM micrograph of the deep etched specimen $S G-R$, graphite spheroid embedded in ferritic matrix.

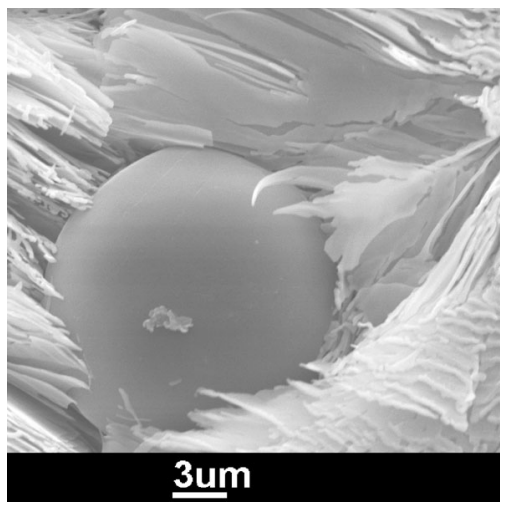

Figure 6. SEM micrograph of the deep etched specimen SG-Sb, graphite spheroid embedded in pearlitic matrix.

surrounded by graphite. A typical Auger spectrum that has been taken from the position marked by the red square in Figure 10a is displayed in Figure 10b.

The constituents are $\mathrm{Si}, \mathrm{C}, \mathrm{Sb}, \mathrm{O}, \mathrm{Cu}$, and $\mathrm{S}$ in order of decreasing concentration. It should be noted the carbon signal probably originates from small graphite flakes; the oxygen might be due to the etching process or is caused by contamination from the atmosphere. At different positions

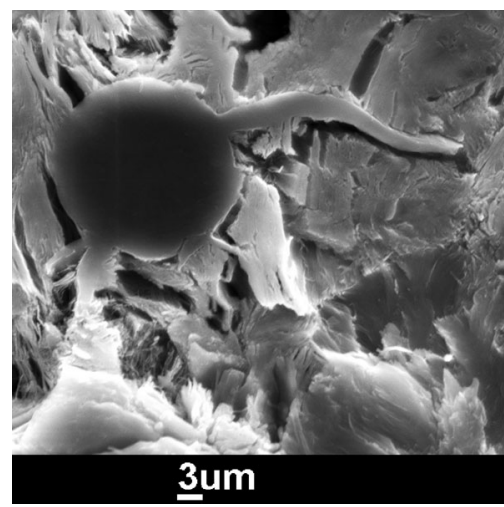

Figure 7. SEM micrograph of the deep etched specimen SG-Sb, graphite spheroid with a lamellar outgrowth in pearlitic matrix.

on the same substrate, the measured concentrations deviate significantly-an evidence of an inhomogeneous composition.

To get a contamination free surface for further investigations, one of the SG-Sb specimens was fractured inside the ultrahigh vacuum system of the AES instrument. Figure 11a shows a typical image from a fractured sample. A graphite spheroid in the lower right position and several spherical recesses where graphite spheres have been pulled out of the matrix by fracturing can be seen. The Auger signal from the graphite spheroids corresponds to clean graphite-like carbon without any other elements. The matrix consists mainly of pearlite with a carbide-like carbon Auger signal, also discernable by the lamellar structure of the matrix. Both signals are given in Figure 11b. It becomes visible, that the peak shapes of the Auger transitions are significantly different for graphite and carbide, which is in correspondence with Reference 8 .

We recorded Auger spectra at several positions of the fractured surfaces, especially at the interfaces between graphite spheres and the matrix and the interface between 


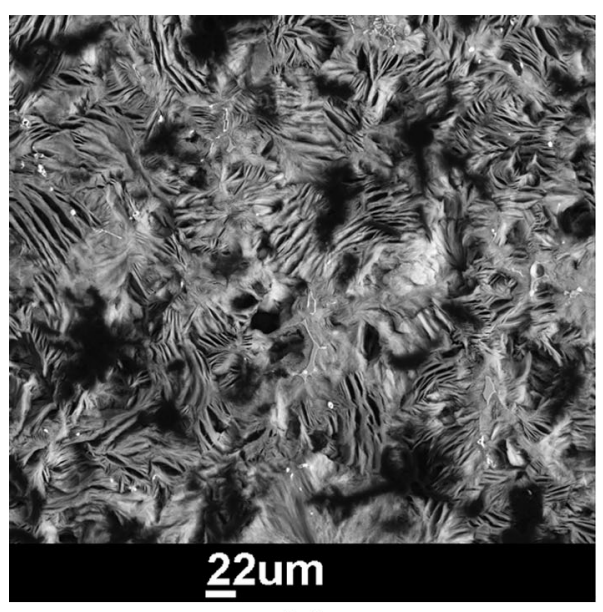

(a)

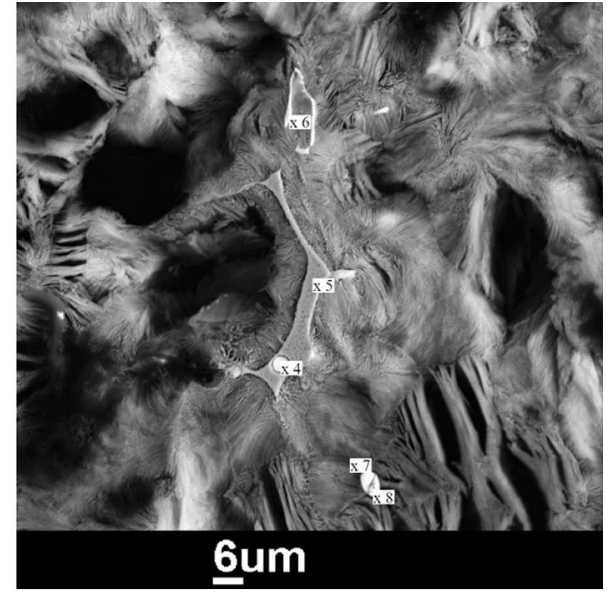

(b)

Figure 8. Microstructures of the deep etched specimen SG-Sb (a) distribution of Sb-containing phases in the matrix (bright dots) and (b) phases of different compositions given in Table 3.

Table 3. Phase Compositions of the Marked Phases in Figure $8 b$ Measured by EDX

\begin{tabular}{lrrrrr}
\hline Element content in at\% & \multicolumn{1}{c}{ X4 } & \multicolumn{1}{c}{ X5 } & \multicolumn{1}{c}{ X6 } & \multicolumn{1}{c}{ X7 } & X8 \\
\hline $\mathrm{Sb}$ & 60.3 & 0.2 & 0.00 & 60.7 & 16.5 \\
$\mathrm{Mg}$ & 6.8 & 0.2 & 0.3 & 4.1 & 21.8 \\
$\mathrm{Si}$ & 6.5 & 1.3 & 0.5 & 10.0 & 19.2 \\
$\mathrm{~S}$ & & 2.4 & 10.7 & 1.6 & 1.4 \\
$\mathrm{P}$ & & 19.0 & & & \\
$\mathrm{Nb}$ & & 1.2 & 27.5 & & \\
$\mathrm{Ti}$ & & & 14.5 & & \\
$\mathrm{Al}$ & & & & & 4.1 \\
$\mathrm{O}$ & & & & & 29.2 \\
$\mathrm{Fe}$ & 24.6 & 74.1 & 33.8 & 21.3 & 9.5 \\
\hline
\end{tabular}

ferrite and cementite layers of the pearlite. We have found $\mathrm{Sb}$ only at the spherical recesses where graphite spheroids have been removed. An AES spectrum recorded from the position marked by a rectangle in Figure 11a is shown in Figure 11c.

Three elements have been detected by AES: Fe, Sb, and C. The carbon signal is a superposition of a contribution of carbon in graphite (residual graphite from the detached sphere) and carbon in carbide (cementite), respectively. This can be concluded from the peak shapes of the Auger transitions that are different for graphite and carbide, shown in Figure 11b. After removing some material by argon ion sputtering, a pure carbide-like carbon Auger signal and iron from pearlite remain in the spectrum (not shown here). The Fe Auger intensity from the recess in Figure 11c is about a factor of two smaller than the $\mathrm{Fe}$ Auger intensity after removal of the $\mathrm{Sb}$ and the graphite-
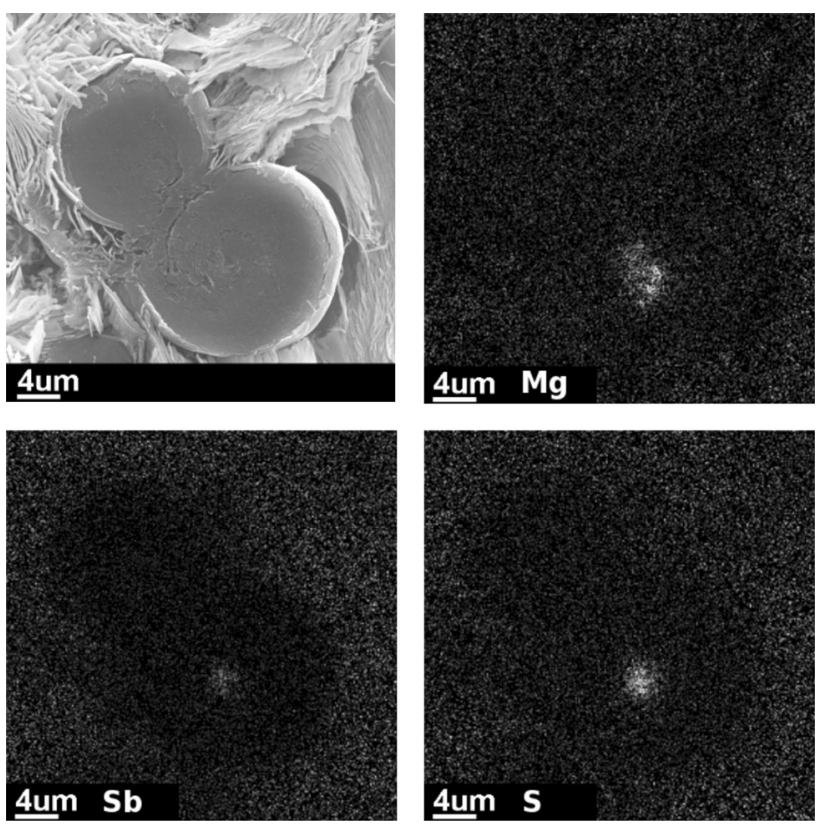

Figure 9. Mapping of a graphite spheroid using SEM with EDX.

like carbon. Considering Auger electrons from $\mathrm{Fe}$ with $705 \mathrm{eV}$ kinetic energy and exponential damping with an inelastic mean free path of $2 \mathrm{~nm}$, this corresponds to a damping of the Fe Auger intensity by an about 1-nm-thick layer. In order to determine a detailed structure of the interface between the graphite spheroid and the surrounding pearlite matrix, we calculated the intensities of the Auger transitions of $\mathrm{Fe}, \mathrm{C}$, and $\mathrm{Sb}$ for several model systems and compared these intensities with our measurements. In these models, the graphite-like carbon should be on top due to its origin from the spheroids. We found a good agreement between the calculations and the experiment for two atomic graphite monolayers and a layer of $\mathrm{Sb}$ 


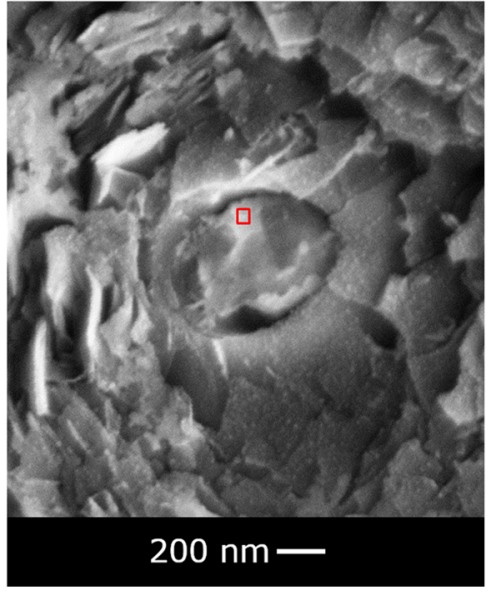

(a)

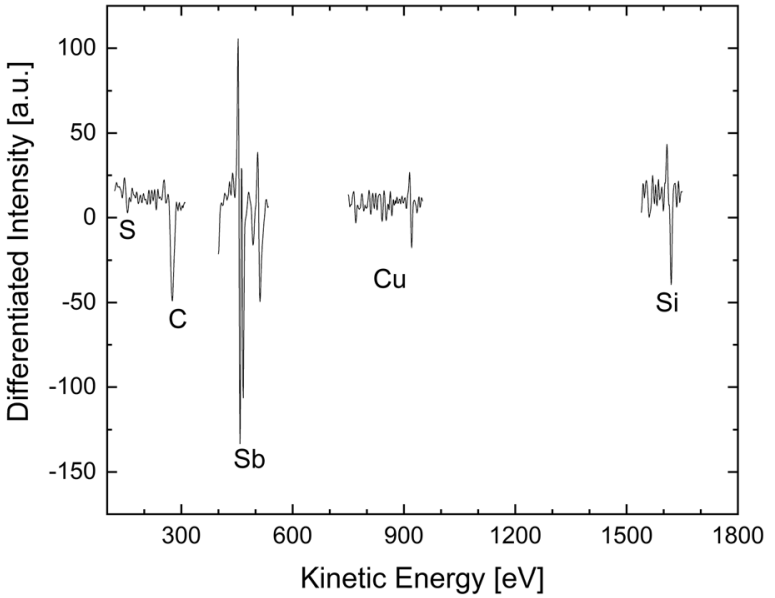

(b)

Figure 10. (a) SEM image of a nucleus from a graphite spheroid and (b) Auger spectrum taken from the spot marked by the red square in the SEM image.

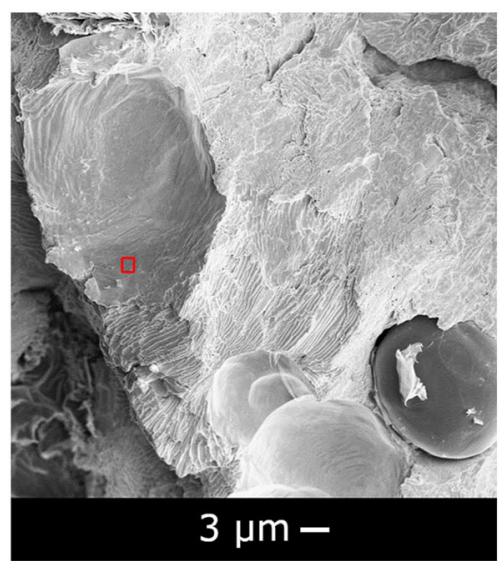

(a)

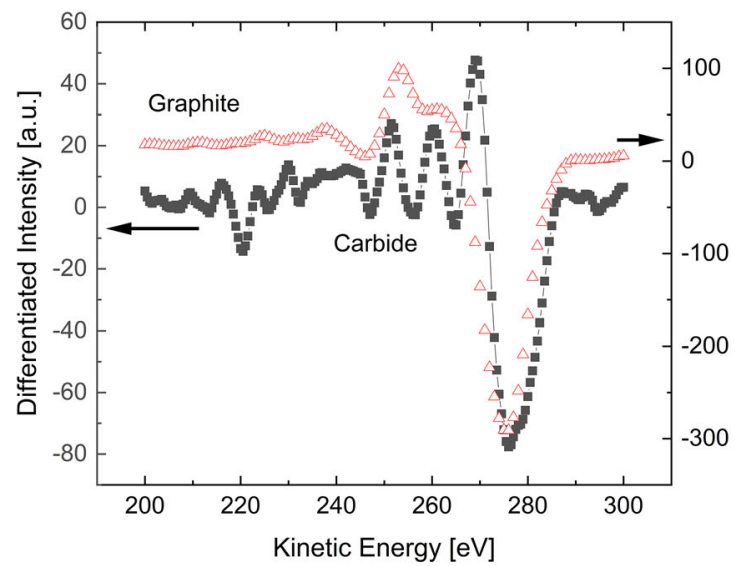

(b)

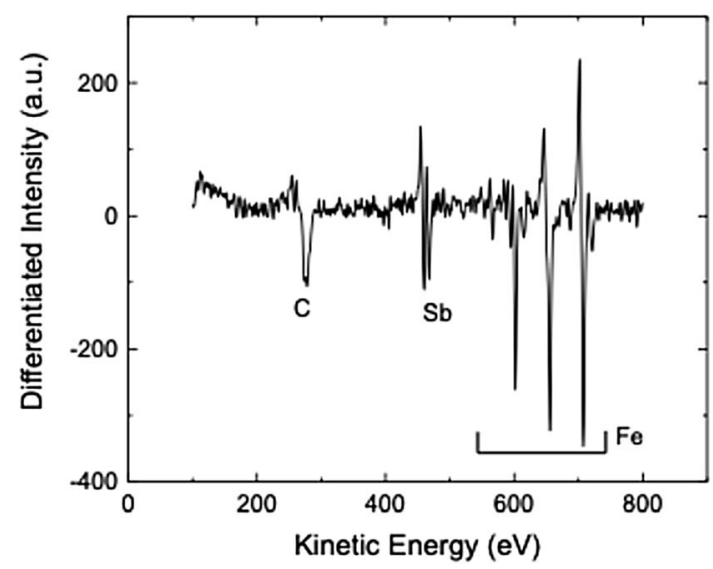

(c)

Figure 11. (a) SEM image of a fractured cast iron specimen containing $S b$, (b) Carbon Auger signal from carbon spheroids (open triangles) and carbide (squares) and (c) Auger spectrum taken from the area marked by the red square in the SEM image (a). 
with a monoatomic height on top of pearlite. The total thickness of such a layer corresponds also quite well to the estimated thickness of the intermediate layer of about $1 \mathrm{~nm}$.

For some regions where we recorded Auger spectra from the spheroids recesses, we found a slightly reduced $\mathrm{Sb}$ Auger intensity. This might be caused by holes in the $\mathrm{Sb}$ layer. Thus, we conclude that the $\mathrm{Sb}$ monolayers occasionally have holes where the matrix is in direct contact with the graphite spheroids.

\section{Discussion}

The eutectic solidification of a near eutectic ductile iron starts with nucleation and growth of graphite. With further solidification, a growing austenite shell will surround the graphite spheroids. The carbon from the melt diffuses through the austenite shell to the graphite spheroids. Antimony seems to be involved in both crystallization processes, in nucleation as well as in growth of graphite.

From thermodynamic calculations, we know that $\mathrm{Sb}$ forms phases with $\mathrm{Mg}$ during solidification. However, in our experimental work with ductile iron $\mathrm{Sb}$ has been found together with $\mathrm{Mg}$ and with other elements like $\mathrm{S}, \mathrm{Si}$, and $\mathrm{Cu}$ in the matrix of ductile iron as well as in the center of graphite spheroids. Thus, Sb-containing phases might also act as substrates for graphite nucleation in addition to many other nucleation effective substrates. That effect can be substantiated by the fact that a higher count of graphite spheroids occurs in the Sb-containing ductile iron than in ductile iron without Sb. The number of the Sb-containing substrates depends on the element concentrations in the melt and on the phase formation energy. We assume that the phase formation with $\mathrm{Sb}$ and the formation of interface $\mathrm{Sb}$ layers around graphite spheroids are competing processes in Sb consumption. Accordingly, there is an interrelation between the number of graphite spheroids, graphite spheroids' diameters and the smoothness of the graphite surface.

The mechanism of the formation of suitable substrates for graphite nucleation has often been analyzed and resulted in many different phases or phase mixtures. In our investigations using AES, the compositions of those substrates inside graphite spheroids seem to be quite inhomogeneous. For a better understanding of the efficacy and mechanism of different substrates on graphite nucleation, further research is necessary. We plan the development of a method to dissect the graphite spheroids to lay open the substrate and a laterally resolved chemical analysis of the substrates layer by layer in a depth profile.

The increased nodule count and a smaller diameter of the spheroids when $\mathrm{Sb}$ has been added to the melt can also be explained by a diffusion barrier formed by the Sb layer in accordance with Kovacs. ${ }^{5}$ He already assumed in 1981 that a thin layer of $\mathrm{Sb}$ at the interface between matrix and graphite works as a diffusion barrier for carbon during the eutectic solidification. Our Auger results confirm the presence of $\mathrm{Sb}$ between matrix and graphite nodules.

However, we think that the Sb layer does not inhibit but rather limits the diffusion of carbon through the $\mathrm{Sb}$ layer. Additionally, $\mathrm{Sb}$ influences the carbon integration after diffusion through the $\mathrm{Sb}$ layer in such a way that the spheres grow in a layer-by-layer mode. The carbon atoms are preferentially attached at step edges of the surface, and/ or the growth of three-dimensional islands is suppressed which is why only two-dimensional islands nucleate at the surface. The extremely smooth surfaces of the carbon spheres in our specimens support this assumption. Furthermore, $\mathrm{Sb}$ and other elements from the fifth main group are well known as surfactants (surface active agents) in the literature. ${ }^{9,10}$ Surfactants are applied in homo-epitaxial as well as in hetero-epitaxial growth in vacuum on semiconductors to improve the layer-by-layer growth (Frank-van der Merwe mode). For our case, we propose the following mechanism for the Sb-mediated growth of spheroidal graphite. The accumulation of $\mathrm{Sb}$ at the interface between graphite spheres and the matrix is probably caused by a reduction of the interface energy by the $\mathrm{Sb}$ interlayer. Hence, it is clear that a continuous $\mathrm{Sb}$ interlayer rather than other $\mathrm{Sb}$ arrangements such as thicker zones of a $\mathrm{Sb}$ enrichment should be formed if enough $\mathrm{Sb}$ from the melt/ austenite could be supplied. If the $\mathrm{Sb}$ layer covers the graphite sphere completely, a consolidated diffusion barrier is formed which reduces the further diffusion of carbon to the graphite surface. The barrier would be more perfect, the smoother the graphite surface is. Rough surfaces and even monoatomic steps would distort the Sb layer, and a distorted layer has probably a larger transmissibility for $\mathrm{C}$ atoms, Figure 12. The black rectangle in Figure 12 symbolizes a section of the graphite sphere. The black circles represent $\mathrm{C}$ atoms forming the outermost graphite layer and as constituent of the surrounding matrix/melt. The $\mathrm{Sb}$ layer (gray circles) covers the graphite sphere and is locally

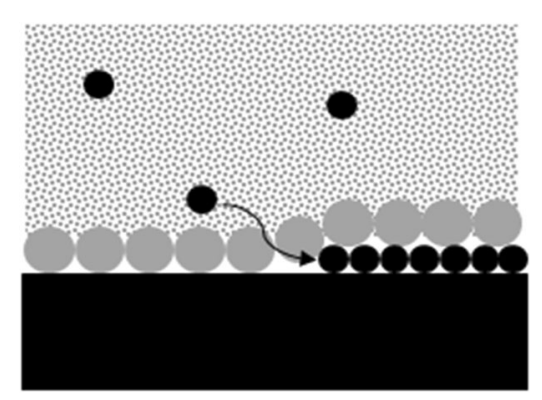

Figure 12. Model of the surfactant-mediated step flow growth on a graphite sphere (cutout in black), black circles: $C$ atoms, gray circles: $S b$ atoms, dotted gray area: austenite/melt. 
strained at the step edge of the top graphite layer. This leads to a higher transmissibility of $\mathrm{C}$ atoms through the $\mathrm{Sb}$ layer and an incorporation of the $\mathrm{C}$ atoms at the step edge. Thus, addition of further $\mathrm{C}$ atoms occurs at steps and would result in a step flow growth at the interface of graphite spheroids and the melt. Therefore, the smooth surfaces of the graphite spheroids are a result of the surfactant-mediated growth of graphite in the early stage of eutectic solidification.

The lamellar outgrowths at some of the graphite spheroids in Figure 7 seem to be inconsistent with this model of a surfactant-mediated growth. We think that in this case the otherwise continuous Sb layers are locally interrupted. This assumption is supported by the reduced Sb Auger signal in some of the recesses as mentioned before. Without the $\mathrm{Sb}$ layer, a diffusion barrier is locally missing and $\mathrm{C}$ atoms from the austenite/melt are attached to the graphite spheroids with an increased growth rate and a lamellar outgrowth can occur.

However, in Reference 11 it is shown that lamellar outgrowths have a preferred growth along the crystallographic $\boldsymbol{a}$ direction, which is different compared to the growth along the $c$ direction of the graphite spheroids. The reason for that change of growth direction is still unknown and subject of further investigations.

\section{Summary}

The effect of $\mathrm{Sb}$ in ductile cast iron was investigated. From thermodynamic calculations, it could be seen that during the eutectic solidification $\mathrm{Sb}$ forms stable precipitations with $\mathrm{Mg}$ and $\mathrm{Sb}$ and is also solute in the matrix. For a better understanding of the effect of $\mathrm{Sb}$ during nucleation and growth of the graphite austenite eutectic casting, experiments with ductile iron containing no and a higher amount of $\mathrm{Sb}$ were carried out. In the experimental investigations, we found a higher graphite nodule count in the specimen with elevated $\mathrm{Sb}$ concentration. Antimony leads to a very smooth surface of the graphite spheroids and occasionally to lamellar outgrowths from graphite spheroids. We have located $\mathrm{Sb}$ in the matrix and in the center of the graphite spheroids as $\mathrm{Mg}$ - and Sb-containing phases and at the interface between graphite spheroids and the pearlitic matrix. It can be concluded that $\mathrm{Sb}$ forms precipitations together with $\mathrm{Mg}$ and other elements which may act as effective substrates for the nucleation of graphite.

A comparison of Auger data with calculations leads to the assumption that $\mathrm{Sb}$ forms a monolayer at the interface between graphite spheroids and matrix. Presumably, the impact of the $\mathrm{Sb}$ monolayer is that it acts as a diffusion barrier for carbon. Carbon atoms are attached preferentially at step edges due to local distortions in the $\mathrm{Sb}$ diffusion barrier resulting in a layer-by-layer growth of the graphite spheroids, which might be the reason for their very smooth surfaces. The occurrence of lamellar outgrowths has been discussed, which might be caused by a local deficiency of $\mathrm{Sb}$ at the interface between graphite and matrix. Here, further investigations are necessary.

\section{Acknowledgements}

Open Access funding provided by Projekt DEAL. We thank Sandra Korte for performing the Auger measurements and Silke Lenk for performing the scanning electron microscopy.

Open Access This article is licensed under a Creative Commons Attribution 4.0 International License, which permits use, sharing, adaptation, distribution and reproduction in any medium or format, as long as you give appropriate credit to the original author(s) and the source, provide a link to the Creative Commons licence, and indicate if changes were made. The images or other third party material in this article are included in the article's Creative Commons licence, unless indicated otherwise in a credit line to the material. If material is not included in the article's Creative Commons licence and your intended use is not permitted by statutory regulation or exceeds the permitted use, you will need to obtain permission directly from the copyright holder. To view a copy of this licence, visit http://creativecommons. org/licenses/by/4.0/.

\section{REFERENCES}

1. W. Baer, Chunky graphite in ferritic spheroidal graphite cast iron: formation, prevention, characterization, impact on properties: an overview. Int. J. Metalcast. (2019). https://doi.org/10.1007/s40962-01900363-8

2. E.N. Pan, C.N. Lin, H.S. Chiou, Effects of lead and solidification conditions on graphite structure of heavy-section DI. AFS Trans. 103, 265-273 (1995)

3. A. Javaid, C. Loper Jr., Production of heavy-section ductile cast iron. AFS Trans. 103, 135-150 (1995)

4. R.K. Buhr, The effects of $\mathrm{Pb}, \mathrm{Sb}, \mathrm{Bi}$ and $\mathrm{Ce}$ on microstructure of heavy section nodular iron castings. AFS Trans. 79, 247-252 (1971)

5. B.V. Kovacs, Pearlite stabilization in cast irons. AFS Trans. 89, 79-96 (1981)

6. B.C. Liu, T.X. Li, Z.J. Rue, X.Y. Yang, E.Q. Huo, C.R. Loper, The role of antimony in heavy-section ductile iron. AFS Trans. 98, 753-757 (1990)

7. D. Briggs, J.T. Grant, Surface Analysis by Auger and $X$-Ray Photoelectron Spectroscopy (IM Publications and Surface Spectra Limited, Chichester, 2003). ISBN 1901019047

8. I.F. Ferguson, Auger Microprobe Analysis (Hilger, Bristol, 1989), pp. 55-99. ISBN 0-85274-147-2

9. D. Kandel, E. Kaxiras, Surfactant mediated crystal growth of semiconductors. Phys. Rev. Lett. 75(14), 2742-2745 (1995) 
10. H. Matsuhata, K. Sakamoto, K. Miki, Behaviors of surfactant atoms on $\mathrm{Si}(001)$ surface. J. Electron Microsc. 53(4), 325-337 (2004)

11. B. Tonn, J. Lacaze, S. Duwe, Degenerated graphite growth in ductile iron. Mater. Sci. Forum 925, 62-69 (2018)
Publisher's Note Springer Nature remains neutral with regard to jurisdictional claims in published maps and institutional affiliations. 